\title{
Buckling characteristics of SiGe layers on viscous oxide
}

\author{
C.-Y. Yu, C.-J. Lee, C.-Y. Lee, and J.-T. Lee \\ Department of Electrical Engineering, National Taiwan University, Taipei, Taiwan 106, Republic of China \\ and Graduate Institute of Electronics Engineering, National Taiwan University, Taipei, Taiwan 106, \\ Republic of China
}

M. H. Liao

Department of Electrical Engineering, National Taiwan University, Taipei, Taiwan 106, Republic of China and Graduate Institute of Electro-Optical Engineering, National Taiwan University, Taipei, Taiwan 106, Republic of China

C. W. Liu $^{\text {a) }}$

Department of Electrical Engineering, National Taiwan University, Taipei, Taiwan 106, Republic of China; Graduate Institute of Electronics Engineering, National Taiwan University, Taipei, Taiwan 106, Republic of China; Graduate Institute of Electro-Optical Engineering, National Taiwan University, Taipei, Taiwan 106, Republic of China; and National Nano Device Laboratories, Hsinchu, Taiwan 300, Republic of China

(Received 15 October 2005; accepted 5 July 2006; published online 21 September 2006)

Buckled SiGe films on viscous oxide with different Ge content are studied by wafer bonding and smart-cut process. Compressively strained SiGe layers on the viscous oxide were relaxed to form the buckled state after thermal treatment. Two-dimensional buckling on blanket films is observed. A higher Ge concentration results in a smaller buckling amplitude and a smaller buckling period. Both buckling amplitude and period increase as oxidation time is increased. A small SiGe film (mesa) area can inhibit buckling. Semiempirical analysis gives the critical area size, below which no buckling is observed in the equilibrium states. The critical area size decreases with increasing Ge concentration and decreasing thickness of SiGe films. () 2006 American Institute of Physics. [DOI: $10.1063 / 1.2345047$ ]

\section{INTRODUCTION}

Implementation of strained $\mathrm{Si}$ on SiGe-on-insulator (SGOI) structures by smart-cut and wafer bonding technologies is beneficial for high speed and low power complementary metal-oxide-semiconductor (CMOS) applications because of the mobility enhancement and low parasitic junction capacitance. ${ }^{1-3}$ Strain relaxation on viscous substrates can probably reduce threading dislocation density by viscous flow of the underlying oxide layer. Borophosphorosilicate glass (BPSG) was reported to be beneficial to engineering the elastic relaxation of strained thin films by viscous flow at high temperature. ${ }^{4}$ However, a strained thin film on viscous oxide is energetically and morphologically unstable during high temperature treatment. There are two possible relaxation mechanisms to relieve the stresses: in-plane expansion and buckling. Both contribute to relieving the stresses individually or concurrently. For metal-oxide-semiconductor field-effect transistor (MOSFET) applications, in-plane expansion is the desired mechanism to obtain a flat and smooth surface. Patterning the strained films on reduced area substrates can facilitate in-plane expansion and suppress the buckling mechanism. However, buckling may be regarded as a useful, optional state of semiconductor materials for device applications. For example, two-dimensional periodicity of buckled film could be utilized as an optical grating device.

In previous work, buckling relaxation of compressively strained SiGe films on viscous oxide has been observed dur-

${ }^{a)}$ Electronic mail: chee@cc.ee.ntu.edu.tw ing long-time furnace annealing in $\mathrm{N}_{2}$ ambient without oxidation, and buckling of compressively strained SiGe mesas was also studied. ${ }^{4,5}$ Dynamic oscillatory analyses of buckled SiGe layers on viscous substrates have been performed by several groups. ${ }^{6-8}$ In this work, two-dimensional buckled SiGe layers were fabricated by oxidation of compressively strained $\mathrm{SiGe}$ on viscous BPSG. The effects of oxidation time, Ge content, and mesa area are studied. The following semiempirical analysis in this paper may be useful in designing devices and to obtain the functional dependence of the phase diagram between buckled films and unbuckled films in terms of Ge content and film thickness.

\section{EXPERIMENTS}

Two $100 \mathrm{~nm}$ defect-free pseudomorphic (fully strained) $\mathrm{Si}_{1-x} \mathrm{Ge}_{x}$ layers were epitaxially grown on $p$-type, $10 \Omega \mathrm{cm}$, (001) orientation silicon substrates and each capped with a $4 \mathrm{~nm}$ Si layer and $50 \mathrm{~nm}$ of BPSG as a "host" wafer. The SiGe layers were grown by ultrahigh vacuum chemical vapor deposition (UHVCVD) at $550{ }^{\circ} \mathrm{C}$ with Ge contents of $10 \%$ and 20\%. On other $p$-type substrates, $700 \mathrm{~nm}$ BPSG is grown to form the "handle" wafer. Hydrogen implantation into the host wafer with a dose of $5 \times 10^{16} / \mathrm{cm}^{2}$, and an energy of $100 \mathrm{keV}$ will create a deep, weakened layer for smart-cut process.

The handle wafer and host wafer were hydrophilicly cleaned in a $\mathrm{NH}_{4} \mathrm{OH}: \mathrm{H}_{2} \mathrm{O}_{2}: \mathrm{H}_{2} \mathrm{O}(0.5: 1: 4)$ solution, rinsed in de-ionized water and, then, initially bonded at room temperature. ${ }^{9}$ Wafer pair was annealed at $800{ }^{\circ} \mathrm{C}$ for $30 \mathrm{~min}$ 

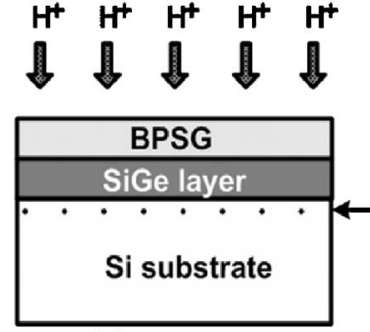

(a) Ion implant

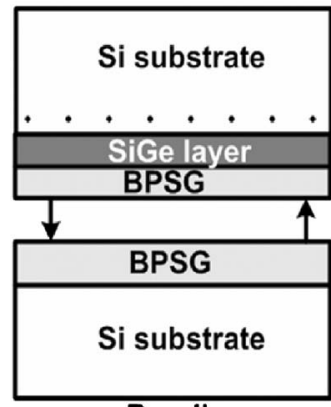

(b) Bonding

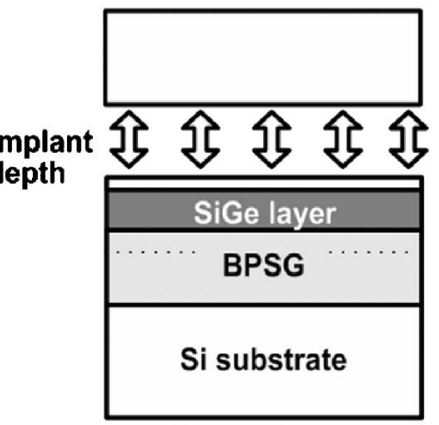

(c) Layer transfer

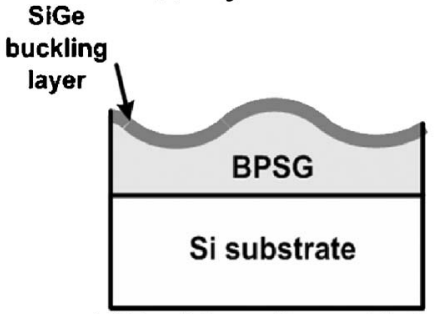

(d)Buckling after oxidation

FIG. 1. Process flow for the fabrication of buckled SiGe layer on BPSG: (a) Ion implantation, (b) wafer bonding, (c) H-induced layer transfer, and (d) buckling formation.

with 1000 SCCM (SCCM denotes cubic centimeter per minute at STP) oxygen flow to strengthen the chemical bonds at the interface. Then $\mathrm{H}_{2}$ blistering severed $\mathrm{SiGe}$ layer from the host wafer, transferring it to the handle wafer (smart-cut process). The separated surfaces exhibited a rootmean-square microroughness of $7.34 \mathrm{~nm}$ after smart-cut process. For comparison, the roughness of the original Si substrate is $<0.5 \mathrm{~nm}$. Then, wafer was etched by $\mathrm{KOH}$ (10\% by weight) solution $^{10}$ to remove selectively $\sim 450 \mathrm{~nm} \mathrm{Si} \mathrm{re-}$ maining on the SiGe/BPSG stack. Blanket SiGe films were patterned into arrays of square mesas with lengths from 20 to $200 \mu \mathrm{m}$ defined by photoresist. The uncovered SiGe area was then etched by $\mathrm{HF}: \mathrm{H}_{2} \mathrm{O}_{2}: \mathrm{CH}_{3} \mathrm{COOH}$ (1: 2: 3) solution $^{11}$ to thin down the $100 \mathrm{~nm} \mathrm{SiGe}$ and form the mesa.

Samples were oxidized with 1000 SCCM oxygen flow at $960{ }^{\circ} \mathrm{C}$ for different times to induce "Ge condensation" 12 in the underside SiGe layer. For anneal times less than $6 \mathrm{~min}$, the condensation only slightly increases the Ge content in the SiGe films, and slightly thins down the layer, as confirmed by transmission electron microscopy (TEM). Thermal oxidation can trigger the relaxation of the SiGe films into their equilibrium states. The buckled state is preferred at thermal equilibrium for thinner films with higher Ge content. The described process for the formation of buckled SiGe layers on viscous SGOI substrates is schematically shown in Fig. 1.

\section{RESULTS AND DISCUSSION}

The compressively strained $\mathrm{SiGe}$ layers on viscous BPSG can relax during the thermal oxidation. Lateral thermal expansion and counterforces caused by the viscous BPSG produce compressive stresses during thermal oxidation at $960{ }^{\circ} \mathrm{C}$. Bending out of the nominal plane by viscous flow of the underlying BPSG layers at a temperature higher

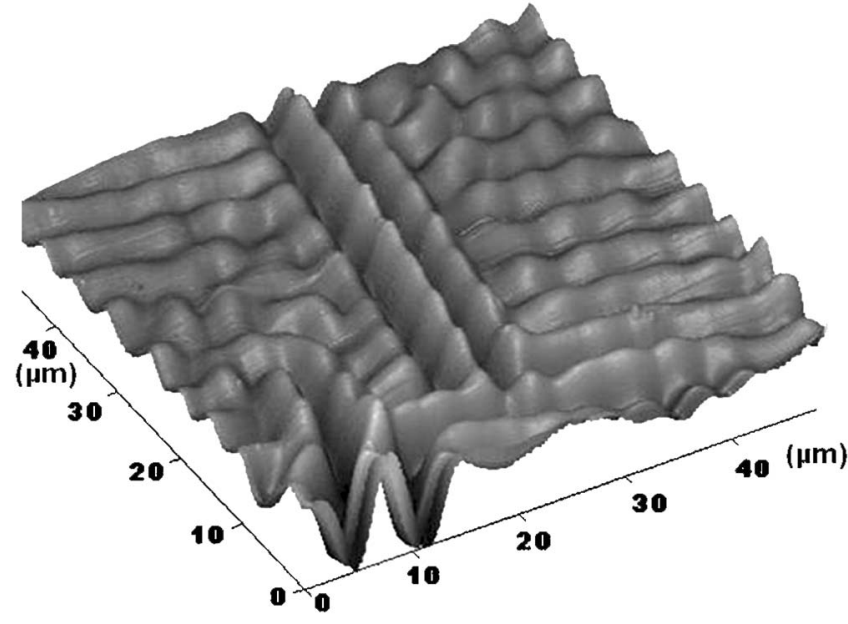

FIG. 2. AFM image of buckled $\mathrm{Si}_{0.8} \mathrm{Ge}_{0.2}$ layers on viscous BPSG. Twodimensional buckling is along the two equivalent $\langle 100\rangle$ directions after 5 min oxidation at $960{ }^{\circ} \mathrm{C}$ with an average period and average amplitude of $\sim 4 \mu \mathrm{m}$ and $\sim 30 \mathrm{~nm}$, respectively.

than the glass transition temperature can relieve compressive stresses in thin semiconductor films. Tapping mode atomic force microscopy (AFM) and optical microscopy were employed to investigate the surface morphologies after relaxation. The buckling phenomenon was observed by AFM, as shown in Fig. 2, where the $\mathrm{Si}_{0.8} \mathrm{Ge}_{0.2}$ film on BPSG was oxidized at $960{ }^{\circ} \mathrm{C}$ for $6 \mathrm{~min}$.

\section{A. Blanket buckling}

Owing to the large shear modulus along $\langle 100\rangle$ directions on the (001) orientation substrates, buckling patterns at the center of blanket SiGe layers on viscous BPSG are twodimensional along two equivalent $\langle 100\rangle$ directions. Figure 3 shows the average buckling period of the SiGe layers. The $\mathrm{Si}_{0.8} \mathrm{Ge}_{0.2}$ layer with initial thickness of $100 \mathrm{~nm}$ has an average buckling period of 2.9 and $4.6 \mu \mathrm{m}$ after 60 and $600 \mathrm{~s}$ oxidation, respectively. The average buckling period increases rapidly for the first $10 \mathrm{~min}$ and then saturates to

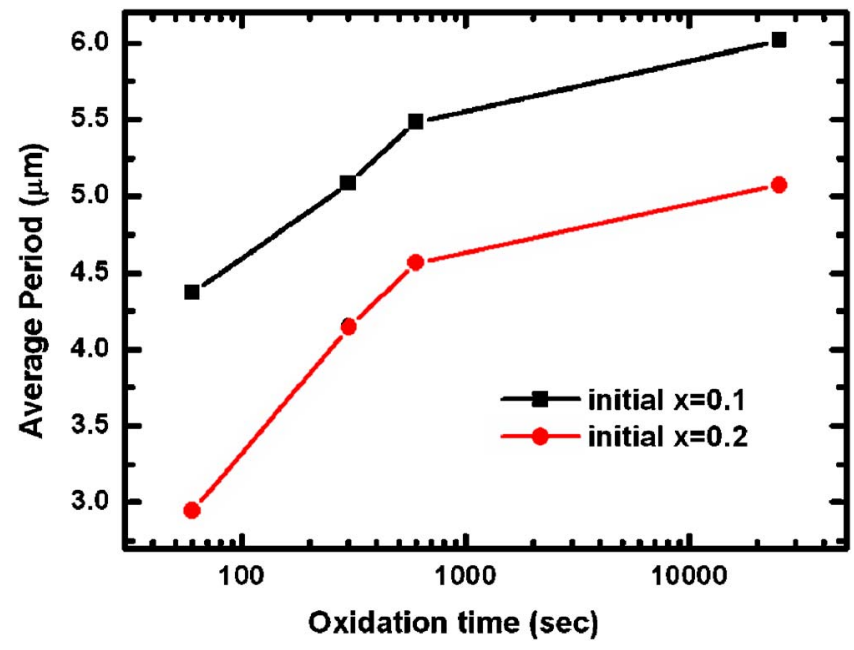

FIG. 3. The average buckling periods of $\mathrm{Si}_{0.9} \mathrm{Ge}_{0.1}$ (squares) and $\mathrm{Si}_{0.8} \mathrm{Ge}_{0.2}$ (circles) on viscous oxide measured by AFM as a function of thermal oxidation time at $960{ }^{\circ} \mathrm{C}$. 


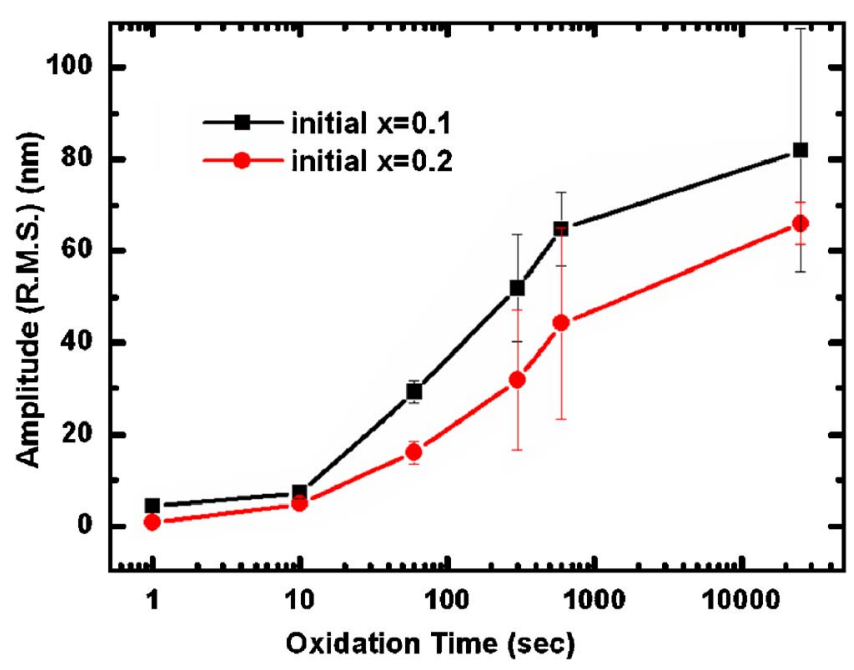

FIG. 4. The average buckling amplitudes of $\mathrm{Si}_{0.9} \mathrm{Ge}_{0.1}$ (squares) and $\mathrm{Si}_{0.8} \mathrm{Ge}_{0.2}$ (circles), measured by $\mathrm{AFM}$, as a function of thermal oxidation time at $960{ }^{\circ} \mathrm{C}$.

$\sim 5.1 \mu \mathrm{m}$ for longer oxidation times. Note that the increasing period of the buckling patterns indicates the permanent relaxation of stored energy in strained film. The $100 \mathrm{~nm}$ $\mathrm{Si}_{0.9} \mathrm{Ge}_{0.1}$ layers show a similar trend to $\mathrm{Si}_{0.8} \mathrm{Ge}_{0.2}{ }^{13}$ but the average buckling period of $\mathrm{Si}_{0.9} \mathrm{Ge}_{0.1}$ layers is larger than that of $\mathrm{Si}_{0.8} \mathrm{Ge}_{0.2}$. A larger strain in the $\mathrm{SiGe}$ film leads to a smaller buckling period.

Figure 4 shows the buckling amplitude of the $\mathrm{Si}_{0.9} \mathrm{Ge}_{0.1}$ and $\mathrm{Si}_{0.8} \mathrm{Ge}_{0.2}$ layers on viscous oxide, measured by $\mathrm{AFM}$ as a function of thermal oxidation time at $960{ }^{\circ} \mathrm{C}$. The buckling amplitude increases with oxidation time. The buckling amplitudes of $\mathrm{Si}_{0.9} \mathrm{Ge}_{0.1}$ and $\mathrm{Si}_{0.8} \mathrm{Ge}_{0.2}$ layers saturate at $\sim 80$ and $\sim 60 \mathrm{~nm}$, respectively. Figures 5(a) and 5(b) show the optical micrographs at the center of $\mathrm{Si}_{0.9} \mathrm{Ge}_{0.1}$ and $\mathrm{Si}_{0.8} \mathrm{Ge}_{0.2}$ layers after $960{ }^{\circ} \mathrm{C} 5$ min oxidation. Figure 5(a) shows that the $\mathrm{Si}_{0.9} \mathrm{Ge}_{0.1}$ sample is uniformly buckled through the whole blanket area, while Fig. 5(b) shows that there are several obvious cracks in the $\mathrm{Si}_{0.8} \mathrm{Ge}_{0.2}$ sample. The $\mathrm{Si}_{0.8} \mathrm{Ge}_{0.2}$ sample releases elastic energy stored in the film by dense waves and some deep cracks. The comparison between $\mathrm{Si}_{0.9} \mathrm{Ge}_{0.1}$ and $\mathrm{Si}_{0.8} \mathrm{Ge}_{0.2}$ samples shows that a higher $\mathrm{Ge}$ content results in the smaller buckling amplitude and a smaller buckling period.

\section{B. Buckling on reduced areas}

Buckling phenomenon is evidently attributed to the relaxation of the elastic energy stored in strained films, while

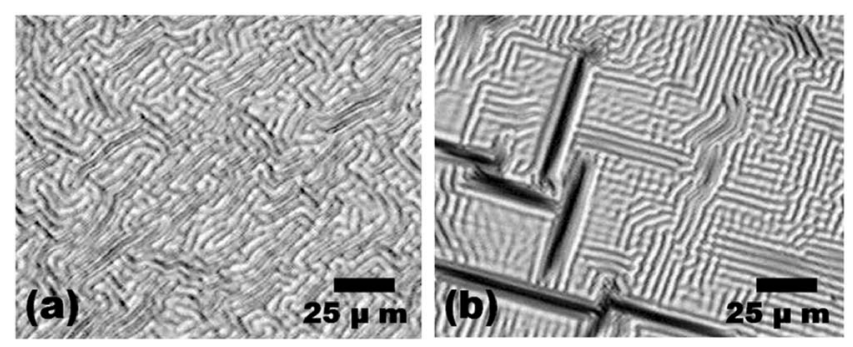

FIG. 5. Optical micrograph image of (a) buckled $\mathrm{Si}_{0.9} \mathrm{Ge}_{0.1}$ and (b) buckled $\mathrm{Si}_{0.8} \mathrm{Ge}_{0.2}$ layers on BPSG. the film thickness is maintained constant along the undulated films. Lateral thermal expansion and counterforces caused by viscous substrates produce compressive stresses and cause bending in the films during rapid thermal oxidation, where the oxidation time is short enough to avoid significant condensation changing the $\mathrm{Ge}$ content and film thickness, as confirmed by TEM. The final thickness of the $\mathrm{Si}_{0.8} \mathrm{Ge}_{0.2}$ film $\left(T_{f}\right)$ is $92.7 \mathrm{~nm}$ observed by TEM after 6 min oxidation at $960{ }^{\circ} \mathrm{C}$, and the final Ge fraction, $x_{f}$, is $21.5 \%$ calculated from the thickness scaling equation $x_{f}=x_{i}\left(T_{i} / T_{f}\right),{ }^{14}$ while the initial Ge content $x_{i}=20 \%$ and the initial thickness $T_{i}$ $=100 \mathrm{~nm}$. To avoid the buckling of the SiGe films, a reduced area of $\mathrm{SiGe}$ on the viscous oxide was used. ${ }^{15}$ As an analogy, a longer rubber eraser is more easily bent by squeezing its two ends. The following semiempirical analysis under initial strain conditions helps to obtain the functional dependence of the phase diagram between buckled films and unbuckled films in terms of $\mathrm{Ge}$ content and film thickness. Considering the buckling of a simple square plate under uniform compressive strain, the displacement of the deflection surface of the compressed film, $w$, can be represented by the double trigonometric series, ${ }^{16-18}$

$$
w=\sum_{m=1}^{\infty} \sum_{n=1}^{\infty} a_{m n} \sin \frac{m \pi x}{a} \sin \frac{n \pi y}{a} .
$$

The displacement $w$ is assumed for simplicity to be zero along the edges of the square pattern $(x=0, x=a, y=0$, and $y=a$ ), since the force is distributed only along the semiconductor/BPSG interface, not at the edge. The expression for the potential energy of buckling, ${ }^{16} U$, is

$$
\begin{aligned}
U= & \frac{1}{2} D \int_{0}^{a} \int_{0}^{a}\left\{\left(\frac{\partial^{2} w}{\partial x^{2}}+\frac{\partial^{2} w}{\partial y^{2}}\right)^{2}\right. \\
& \left.-2(1-v)\left[\frac{\partial^{2} w}{\partial x^{2}} \frac{\partial^{2} w}{\partial y^{2}}-\left(\frac{\partial^{2} w}{\partial x \partial y}\right)^{2}\right]\right\} d x d y, \\
D= & \frac{E t_{\text {SiGe }}^{3}}{12\left(1-v^{2}\right)}
\end{aligned}
$$

where $E$ is Young's modulus, and $v$ is Poisson ratio of the film. It can be shown that the integral of the second term in the brackets in Eq. (2) vanishes, and we obtain

$$
\begin{aligned}
U= & \frac{1}{2} D \int_{0}^{a} \int_{0}^{a}\left\{\sum _ { m = 1 } ^ { \infty } \sum _ { n = 1 } ^ { \infty } a _ { m n } \left(\frac{m^{2} \pi^{2}}{a^{2}}\right.\right. \\
& \left.\left.+\frac{n^{2} \pi^{2}}{a^{2}}\right) \sin \frac{m \pi x}{a} \sin \frac{n \pi y}{a}\right\}^{2} d x d y .
\end{aligned}
$$

Only the squares of the terms of the infinite series give nonzero integrals and the cross terms become zero after the integration. Then, observing that

$$
\int_{0}^{a} \int_{0}^{a} \sin ^{2} \frac{m \pi x}{a} \sin ^{2} \frac{n \pi y}{a} d x d y=\frac{a^{2}}{4},
$$

we obtain 


$$
U=\frac{a^{2}}{8} D \sum_{m=1}^{\infty} \sum_{n=1}^{\infty} a_{m n}^{2}\left(\frac{m^{2} \pi^{2}}{a^{2}}+\frac{n^{2} \pi^{2}}{a^{2}}\right)^{2}
$$

On the other hand, the work done ${ }^{16}$ by the compressive forces to form the buckling state is

$$
T=\frac{1}{2} \int_{0}^{a} \int_{0}^{a}\left[N\left(\frac{\partial w}{\partial x}\right)^{2}+N\left(\frac{\partial w}{\partial y}\right)^{2}+2 N \frac{\partial w}{\partial x} \frac{\partial w}{\partial y}\right] d x d y
$$

where $N$ is the magnitude of compressive force per unit length at the edge, which is not the exact situation we have now. In our sample, the force originates from counterforce due to the underlying oxide to produce compressive stress during thermal treatment. The force in our samples was distributed only along the interface between $\mathrm{SiGe}$ layers and viscous oxide. Similarly, substituting the expression for $w$ in Eq. (1) into Eq. (7), we obtain

$$
T=\frac{a^{2}}{8} N \sum_{m=1}^{\infty} \sum_{n=1}^{\infty} a_{m n}^{2} \frac{\pi^{2}}{a^{2}}\left(m^{2}+n^{2}\right) .
$$

The stored strain energy equals the work, $U=T$,

$$
\begin{aligned}
& \frac{a^{2} \pi^{4}}{8} D \sum_{m} \\
& \quad \sum_{n=1}^{\infty} a_{m n}^{2}\left(\frac{m^{2}+n^{2}}{a^{2}}\right)^{2}=\frac{a^{2} N}{8} \sum_{m=1}^{\infty} \sum_{n=1}^{\infty} a_{m n}^{2} \frac{\pi^{2}}{a^{2}}\left(m^{2}+n^{2}\right) .
\end{aligned}
$$

Thus, the magnitude of the compressive force per unit length at the edge, $N$, becomes

$$
N=\frac{\pi^{2} D \sum_{m=1}^{\infty} \sum_{n=1}^{\infty} a_{m n}^{2}\left(m^{2}+n^{2}\right)^{2}}{a^{2} \sum_{m=1}^{\infty} \sum_{n=1}^{\infty} a_{m n}^{2}\left(m^{2}+n^{2}\right)} .
$$

For a minimum in Eq. (10), all coefficients $a_{m n}$, except $a_{11}$, have to be zero, and the minimum value of $N$ occurs when $m=n=1$, i.e.,

$$
N_{\mathrm{cr}}=\frac{2 \pi^{2} D}{a^{2}} .
$$

Since a square geometry is considered, $N_{\mathrm{cr}}$ is the force required to create the fundamental mode, i.e., $m=1$ and $n=1$. By symmetry arguments due to the square pattern, the modes of $m=1, n=0$ and $m=0, n=1$ are assumed not to occur. The 2 in the numerator of Eq. (11) would change to 1 if these modes could occur. To translate the distributed force into the edge force $N$ in our sample, we assume that $N=\alpha \times \sigma$ $\times t_{\mathrm{SiGe}}$, where $\sigma$ is the stress on the film, $\alpha$ is a proportionality constant, and $t_{\mathrm{SiGe}}$ is the film thickness. A thicker film leads to a larger force at the edge. The critical value of the compressive stress is

$$
\sigma_{\mathrm{cr}}=\frac{\pi^{2} E}{6 \alpha\left(1-v^{2}\right)} \frac{t_{\mathrm{SiGe}}^{2}}{a^{2}}
$$

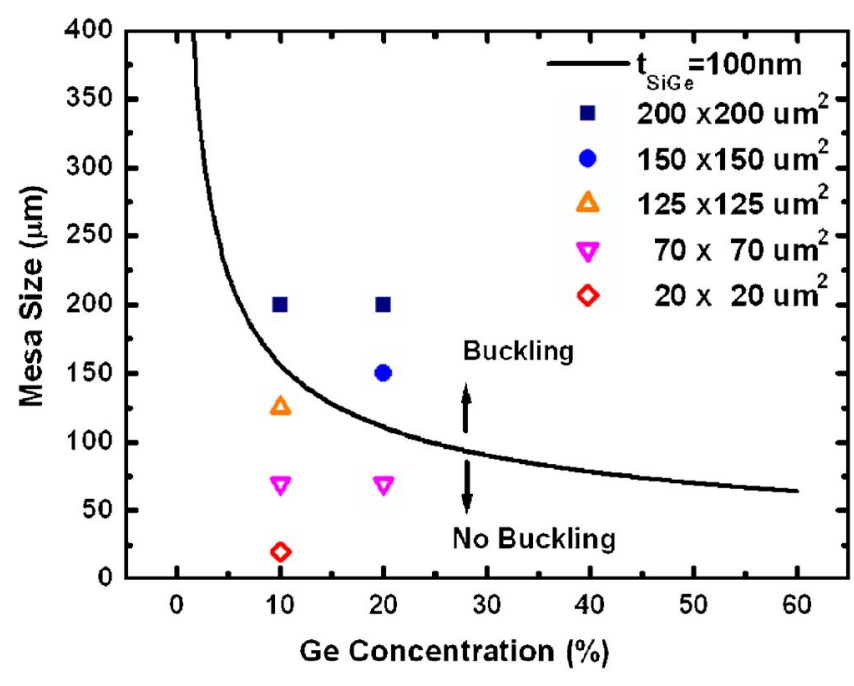

FIG. 6. Critical mesa size vs Ge concentration with a SiGe thickness of $100 \mathrm{~nm}$. Solid symbols indicate the buckled films, and open symbols indicate the unbuckled films.

$$
\sigma_{\mathrm{cr}}=\varepsilon \times E=(0.0417 x) \times E,
$$

where $\varepsilon$ is the strain in the film, and $\alpha=0.036$ to fit the experimental data in Fig. 6. Since the $\mathrm{Si}_{1-x} \mathrm{Ge}_{x}$ film was originally completely strained on $\mathrm{Si}, \varepsilon=0.0417 x$, which is the misfit between $\mathrm{Si}_{1-x} \mathrm{Ge}_{x}$ and $\mathrm{Si}$.

Figure 6 shows the experimental data from 20 $\times 20$ to $200 \times 200 \mu \mathrm{m}^{2}$ mesas after $960{ }^{\circ} \mathrm{C}$ oxidation for 6 min. Mesa sizes larger than the critical curve produce the buckling at the thermal equilibrium state. According to Eq. (12), the critical mesa size depends on the Ge concentration and the mesa thickness. The maximum mesa size to avoid buckling can be increased by decreasing the Ge content and increasing the thickness of the SiGe layers $\left(t_{\mathrm{SiGe}}\right)$.

The initial film cannot reach the thermal equilibrium due to the low temperature $\left(800^{\circ} \mathrm{C}\right)$ of the thermal bonding. The thermal oxidation at higher temperature $\left(960{ }^{\circ} \mathrm{C}\right.$ for $\left.6 \mathrm{~min}\right)$ can drive films to reach the thermal equilibrium state. Figures 7(a) and 7(b) show the optical micrograph for 200 $\times 200 \mu \mathrm{m}^{2}$ mesas of $\mathrm{Si}_{0.8} \mathrm{Ge}_{0.2}$ layers on viscous oxide before and after thermal treatment at $960{ }^{\circ} \mathrm{C}$, and Figs. 8(a) and 8(b) show the $70 \times 70 \mu \mathrm{m}^{2}$ samples. The 200 $\times 200 \mu \mathrm{m}^{2}$ mesa becomes buckled after the oxidation, while the $70 \times 70 \mu \mathrm{m}^{2}$ mesa remains flat.

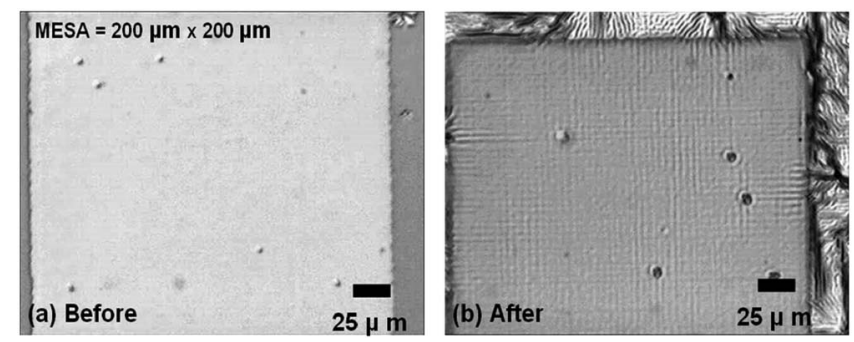

FIG. 7. Optical micrograph image of $200 \times 200 \mu \mathrm{m}^{2}$ mesas of $\mathrm{Si}_{0.8} \mathrm{Ge}_{0.2}$ layers on viscous oxide (a) before and (b) after thermal oxidation at $960{ }^{\circ} \mathrm{C}$ for $6 \mathrm{~min}$. 

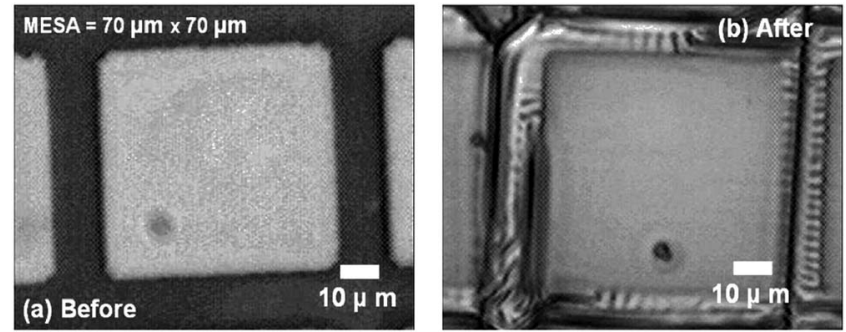

FIG. 8. Optical micrograph image of $70 \times 70 \mu \mathrm{m}^{2}$ mesas of $\mathrm{Si}_{0.8} \mathrm{Ge}_{0.2}$ layers on viscous oxide (a) before and (b) after thermal oxidation at $960^{\circ} \mathrm{C}$ for $6 \mathrm{~min}$.

\section{CONCLUSIONS}

Stress relaxation during thermal oxidation at high temperature through buckling is observed, when the original SiGe layers are compressively strained. As the thermal oxidation time increases, both the buckling amplitude and period increase. The exact control of buckling patterns and location is not possible at present, and this would limit the device applications employing the buckled state of materials. However, an unbuckled film can be produced by limiting the SiGe thickness, Ge concentration, and SiGe mesa area. The empirical formula of the critical mesa size derived in this paper may be useful in designing devices with unbuckled SiGe layers.

\section{ACKNOWLEDGMENTS}

The authors would like to acknowledge Dr. P. S. Chen at ERSO/ITRI for UHV/CVD growth. The proofread by Dr.
Temple and Dr. Maikap is highly appreciated. This work was supported National Science Council, Taiwan, ROC under contract Nos. 91-AT-7-002-001 and 91-2622-E-002-013CC3, and Taiwan Semiconductor Manufacturing Company (TSMC) university program.

${ }^{1}$ J. J. Welser, J. L. Hoyt, and J. F. Gibbons, IEEE Electron Device Lett. 15, 100 (1994)

${ }^{2}$ K. Rim, J. J. Welser, J. L. Hoyt, and J. F. Gibbons, Tech. Dig. - Int. Electron Devices Meet. 1995, 517.

${ }^{3}$ T. Mizuno et al., Tech. Dig. - Int. Electron Devices Meet. 1999934.

${ }^{4}$ K. D. Hobart, F. J. Kub, M. Fatemi, M. E. Twigg, P. E. Thompson, T. S. Kuan, and C. K. Inoki, J. Electron. Mater. 29, 897 (2000).

${ }^{5}$ R. Oberhuber, G. Zandler, and P. Vogl, Phys. Rev. B 58, 9941-9947 (1998).

${ }^{6} \mathrm{H}$. Yin et al., J. Appl. Phys. 91, 9716 (2002).

${ }^{7}$ J. Liang, R. Huang, H. Yin, J. C. Sturm, K. D. Hobart, and Z. Suo, Acta Mater. 50, 2933-2944 (2002)

${ }^{8}$ R. Huang and Z. Suo, J. Appl. Phys. 91, 1135 (2002).

${ }^{9}$ Q.-Y. Tong and U. Gosele, Semiconductor Wafer Bonding (Wiley, New York, 1999).

${ }^{10} \mathrm{~K}$. C.-C. Wu, "Novel etch-stop materials for silicon micromachining" M. Eng. dissertation, Massachusetts Institute of Technology, Cambridge, 1997.

${ }^{11}$ T. K. Carns, M. O. Tanner, and K. L. Wang, J. Electrochem. Soc. 142, 1260 (1995).

${ }^{12}$ T. Tezuka, N. Sugiyama, T. Mizuno, and S. Takagi, Symp. VLSI Tech. Dig., 2000, pp. 210-211.

${ }^{13}$ C.-Y. Yu, P.-W. Chen, M.-H. Liao, S.-R. Jan, and C. W. Liu, Appl. Phys. Lett. 86, 011909 (2005).

${ }^{14}$ J. Liang, R. Huang, H. Yin, J. C. Sturm, K. D. Hobart, and Z. Suo, Acta Mater. 50, 2933-2944 (2002).

${ }^{15}$ H. Yin et al., J. Appl. Phys. 91, 9716 (2002).

${ }^{16}$ S. P. Timoshenko and J. M. Gere, Theory of Elastic Stability (McGrawHill, New York, 1961)

${ }^{17}$ J. M. Gere, Mechanics of Materials (Brooks-Cole, Belmont, MA, 2001).

${ }^{18} \mathrm{~S}$. Timoshenko and S. Woinowsky-Krieger, Theory of Plates and Shells (McGraw-Hill, New York, 1959). 